\title{
Chillida y Ullán re-escriben el libro (en) blanco: Adoración
}

\section{Chillida and Ullán re-write the (in)-blank book: Adoración}

\author{
$\mathrm{M}^{\mathrm{a}}$ Isabel CARRASCO CASTRO \\ Marist College \& Stetson University in Madrid \\ isabelakis@yahoo.es
}

\section{Resumen}

Este artículo tiene como objetivo dar a conocer Adoración (Libro blanco), un libro de artista concebido por José-Miguel Ullán en colaboración con Eduardo Chillida en 1977. El estudio de las circunstancias vitales y creativas de cada uno de los co-autores en el periodo en que se editó el libro, así como el análisis de su contexto, formato y contenido, pasa por la reflexión sobre ¡Adentro! de Unamuno y Haschisch de Benjamin, y arroja cierta luz sobre este proyecto complejo cuyo significado aún alberga muchos interrogantes. Pero, sobre todo, la obra ofrece otra perspectiva acerca de conceptos clave del universo creativo de Chillida -y del gráfico en particular- como son la idea del libro de artista, el valor del blanco en la obra sobre papel, la simbología de la mano y la relevancia de la religión.

Palabras clave: Eduardo Chillida, José-Miguel Ullán, Benjamin (Haschisch), Unamuno (;Adentro!), Adoración (Libro de Artista), la mano, lo blanco. 


\begin{abstract}
The aim of this article is to release Adoración (Libro Blanco), an Artist's Book conceived by José-Miguel Ullán in collaboration with Eduardo Chillida 1977. The study of the personal and creative life circumstances of each of the co-authors in the period when the Book was published, along with the analysis of its context, format and content, lead us to the texts: ;çAdentro! by Unamuno and Haschisch by Benjamin, and sheds some light on this complex project whose meaning still holds many questions. In addition, the artwork offers a new perspective on some key concepts of Chillida's creative universe -and on the graphic one in particular-such as the idea of Artist's Book, the value of white color in the work on paper, the symbolism of the hand and the relevance of religion.
\end{abstract}

Keywords: Eduardo Chillida, José-Miguel Ullán, Bejamin (Haschisch), Unamuno (;Adentro!), Adoración (Artist's Book), the hand, the white.

\title{
Introducción
}

Como tantos artistas españoles de aquellos años, Chillida ${ }^{1}$ y Ullán ${ }^{2}$ se habían mudado a la ciudad que aún se consideraba en cierto modo la capital del arte, con el fin de buscar un ambiente creativo más abierto que el de la España franquista. Por un lado, Chillida se trasladó a París en 1948 donde comenzará a practicar la figuración con sus esculturas de yeso y terracota inspiradas en la luz mediterránea de Grecia. Tras algunas idas y venidas, regresaría con su familia al País Vasco en 1951 para quedarse definitivamente. Por otro lado, Ullán ${ }^{3}$ se exiliará en la capital francesa entre 1966 y 1976, tiempo

\footnotetext{
${ }^{1}$ Agradezco desde aquí la ayuda documental prestada a la Fundación Chillida-Leku.

${ }^{2}$ Mi sincero agradecimiento una vez más a Manuel Ferro de la editorial Ave del Paraíso por su inestimable ayuda.

${ }^{3}$ José-Miguel Ullán, 30 de octubre 1944, Villarino de los Aires, Salamanca- 2009 Madrid. En paralelo con la actividad poética, destacó en el periodismo cultural desde París, así como tras su regreso a España. Columnista del diario El País, Subdirector de Diario 16 y fundador de su suplemento "Culturas", creó la colección de Poesía Cátedra. Responsable de diversos programas culturales en Radio Nacional de España y Televisión Española, organizó numerosas exposiciones de artes plásticas y formó parte del comité de selección de arte en diferentes exposiciones. Fue traductor, poeta, y creador. Fundó junto a Manuel Ferro la editorial "Ave del Paraíso". Para cuestiones biográficas, remitimos al texto con el que se abre el catálogo de la exposición retrospectiva dedicada a su obra plástica: Ferro, M., (comisario y editor) JoséMiguel Ullán: palabras iluminadas, Madrid, La Casa Encendida, 2012.
} 
durante el cual estudió en la École Pratique des Hautes Études, participando en los cursos de Pierre Vilar, Lucien Goldmann y Roland Barthes. Junto a su actividad poética ${ }^{4}$, Ullán desarrolló el periodismo cultural desde París; allí, además de entrar en contacto con el grupo de creadores españoles exiliados -Antonio Saura, María Zambrano, José Ángel Valente, Antoni Tàpies, Eusebio Sempere, o Pablo Palazuelo entre otros-, ambos tuvieron la oportunidad de conocer a figuras como Edmond Jabès, Severo Sarduy, o Margueritte Duras, con las que cada uno acabaría colaborando en proyectos diversos.

En este contexto cultural parisino fue precisamente donde Eduardo Chillida y José-Miguel Ullán se conocieron en 1973 en el taller de la pareja de grabadores y editores Lydie y Robert Dutrou ${ }^{5}$, que colaboraban con la famosa Galería Maeght ${ }^{6}$, y quienes cuatro años más tarde, editarían el libro de artista que el poeta había concebido en colaboración con el vasco. Desde ese momento surgió una amistad entre ambos que duró hasta el fallecimiento de Chillida en $2002^{7}$ y que les hizo coincidir en varios actos públicos de los que ha quedado testimonio fotográfico ${ }^{8}$.

\footnotetext{
${ }^{4}$ Hasta Adoración, Ullán había publicado los siguientes libros de poesía: El jornal (1965), Amor peninsular (1965), Un Humano Poder (1966), Mortaja (1970), Antología Salvaje (1970), Cierra los ojos y abre la boca (1970), Maniluvios (1972), Frases (1975), De un caminante enfermo que se enamoró donde fue hospedado (1976), Alarma (1976).

${ }_{5}^{5}$ Ambos eran los encargados de estampar todas las ediciones de los grabados de la prestigiosa galería Maeght; desde Chagall a Tàpies pasando por Chillida o Miró. Posteriormente, Lydie y Robert Dutrou se convertirían, además, en los editores de la galería.

${ }^{6}$ Sobre la importancia de esta sala de exposiciones parisina y su galerista, dice Chillida: "Aimé Maeght era un símbolo de vanguardia en aquella época, un hombre que concebía la sala de exposición como centro de reunión y tertulia cultural. Yo era el más joven del equipo y hasta su muerte, en 1982, fuimos grandes amigos" Chillida, E., Escritos, Madrid, La Fábrica, 2005, p. 91. http://www.maeght.com

${ }^{7}$ José-Miguel Ullán fallecería 7 años más tarde, el 23 de mayo de 2009, y desde la página web de la Fundación Chillida-Leku se publicó una nota en recuerdo a la amistad que les había unido: "Adiós a José-Miguel Ullán: El Museo Chillida-Leku quiere recordar la figura del poeta José Miguel Ullán (Salamanca, 1944 - Madrid, 2009) fallecido el pasado sábado. Se le ha definido como un poeta "transversal" porque fue muy frecuente en su trayectoria la colaboración con artistas plásticos y músicos. Concretamente en 1977, Eduardo Chillida realizó tres aguafuertes para acompañar la obra poética de Ullán Adoración, traducida al francés por Marguerite Duras. El libro fue editado en París por Robert y Lydie Dutrou. Los libros de artista de Chillida eran concebidos como un diálogo directo entre escultor y escritor". http://www.museochillidaleku.com/Detalle-Noticia-General.207+M596215ef8a3.0.html

${ }^{8}$ Algunos de estos actos públicos fueron: el encuentro Symposium Chillida en el Palacio de Miramar de San Sebastián dirigido por Kosme de Barañano, donde Ullán intervino con un texto que ocupa parte de este artículo y que analizaremos más adelante; la exposición antológica de la obra gráfica de Eduardo Chillida en La Casa de la Moneda de Madrid; la exposición de Europalia '85 España en Bruselas (Ullán seleccionó y prologó los textos de Gaston Bachelar, Octavio Paz, Jacques Dupin y del propio Eduardo para el catálogo); el Centenario de San Juan de la Cruz y la inauguración del Museo de Arte contemporáneo de Lanzarote. (Fuente: conversaciones con Manuel Ferro).
} 


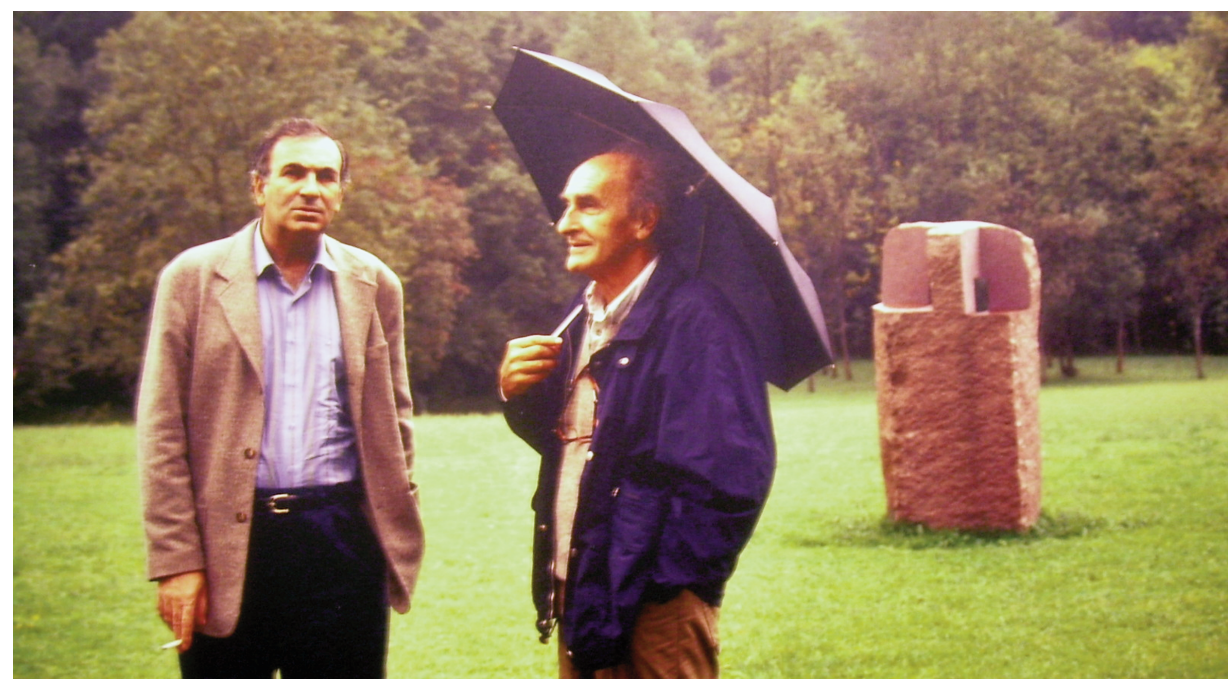

José Miguel Ullán y Eduardo Chillida en museo Chillida-leku, 1995

(Fotografía de Manuel Ferro)

Es de sobra conocido que, a lo largo de su vida, Chillida realizó bastantes libros de bibliofilia en ocasiones acompañado de filósofos, escritores u otros artistas 9 . De hecho, por aquel entonces, ya había comenzado la obra Derrière le miroir y había terminado: Le chemin des devins, suivi de Ménerbes con André Frénaud (1966), Meditation in Kastilien con Max Holzer (1968), Die Kunst und der Raum con Martin Heidegger (1969), Más allá con Jorge Gillén (1973) y, finalmente, Le Sujet et la clairière de son corps con Charles Racine (1973). Por otra parte, la tendencia natural de su escritura hacia la imagen plástica llevó a Ullán, de igual modo, a liderar varios proyectos en el terreno del libro de artista o en colaboración con ilustradores. De hecho, para $1977^{10}$ Ullán también había publicado algunos trabajos de esta naturaleza como Adoptio in fratem con Antonio Saura (1976) o Alarma con Eusebio Sempere (1976).

En este artículo vamos a analizar Adoración (Libro blanco), un proyecto ideado por José-Miguel Ullán e ilustrado por Eduardo Chillida que, sorprendentemente, no ha suscitado demasiado interés por parte de los críticos hasta el momento - de ahí la ausencia total de estudios monográficos y la necesidad de afrontar un estudio como el presente.

No cabe ninguna duda de la dificultad que entraña en general la interpretación de la obra de Ullán, siempre inclasificable, escurridiza, fascinante y

\footnotetext{
${ }^{9}$ García Velilla, J. I., y González Lavagne, J., Los libros de artista de Chillida: una constelación estética, Madrid, Biblioteca Nacional, 2007.

${ }^{10}$ Ese mismo año, Rayuela también publica Las Soledades de Francisco Peinado.
} 
difícil de etiquetar. Además, a la complejidad de su escritura se le une el hecho de presentarse junto una interesantísima actividad plástica en paralelo que él mismo llamó "Agrafismos": imágenes que surgían cuando la escritura no llegaba, durante la espera de la palabra, o entre palabra y palabra 11 .

Dada la escasez de fuentes con las que contamos y lo oscuro de su naturaleza, con este breve estudio no se pretenden agotar las indagaciones en torno a este libro de artista pero sí procuraremos, en primer lugar, dedicarle una atención más que merecida, además de dilucidar las ideas clave que alberga entre sus hojas de papel: el juego del blanco y el negro en la imagen y la escritura, la simbología de la mano y el texto religioso como inspiración. Aspectos, todos ellos, característicos de gran parte de la obra de Chillida pero que, en este caso particular, y tal y como se manifiestan en Adoración, vinculan a ambos artistas íntimamente en su modo de entender el arte.

\section{Adoración (Libro Blanco), 1977}

Adoración se enmarca dentro de un proyecto de José-Miguel Ullán de mayor envergadura, que incluye seis libros con seis artistas diferentes englobados bajo el título Funeral Mal. Ullán dedicó ocho años -desde 1972 hasta 1985- a esta colección durante los cuales, obviamente, siguió trabajando en otras producciones literarias; de hecho podemos considerar Funeral Mal como el telón de fondo de sus preocupaciones a cerca de la escritura y la imagen que se irán viendo reflejadas en otras publicaciones de estos años ${ }^{12}$. Los libros que componen Funeral Mal ${ }^{13}$ fueron publicados en París con traducción francesa de los textos, y expuestos en España en la I Feria ARCO en 1982:

${ }^{11}$ La Casa Encendida celebró una esperada y merecida exposición retrospectiva de la obra plástica de Ullán en junio de 2012. Los resultados se pueden consultar en el catálogo: Ferro 2012 op. cit. (nota 3 ).

${ }_{12}$ Paralelamente a estas colaboraciones, Ullán desarrolla algunos de sus libros más innovadores en cuanto a su escritura y la relación de ésta con la imagen: Frases (1975) y en De un caminante enfermo que se enamoró donde fue hospedado (1976). Estas obras llevarán a Órganos dispersos (2000) y Ni mu (2002); en esta última, donde desde el propio título se advierte la ausencia de palabra, culmina el proceso de silenciación progresiva del lenguaje hasta convertirlo en mancha opaca.

${ }^{13}$ Ardicia -libro rojo- (con Pablo Palazuelo), hay poemas visuales que son como un papiro quemado donde sólo se pueden leer fragmentos de textos en árabe, chino, latín o griego, además de sistemas de caracteres gráficos geométricos inventados. Acorde -libro amarillo- (con Vicente Rojo) es una disertación en torno al color amarillo: plástico para Rojo y anagramático para Ullán a partir de la palabra "amarillo". Asedio -libro negro- (con Antonio Saura) emplea textos manipulados sobre los que se ha garabateado dificultando la lectura e imponiendo lo gestual dibujístico e ilegible sobre la supuesta nitidez del texto serio tipográfico. Anular -color 
- Adoración, Libro blanco, con grabados de Eduardo Chillida, 1972-1978.

- Ardicia, libro rojo, con grabados de Pablo Palazuelo, 1973-1978.

- Acorde, Libro amarillo, con grabados de Vicente Rojo, 1973-1978.

- Asedio, Libro negro, con grabados de Antonio Saura, 1975-1980.

- Anular, Libro color tierra, con grabados de Antoni Tàpies, 1975-1981.

- Almario, Libro azul, con grabados de Joan Miró, 1985.

Cada uno de estos libros requeriría un estudio independiente pero, por comentar algunos aspectos generales, lo primero que encontramos en común es que comiencen con la letra "A", tal vez como señal de inicio de un sistema o planteamiento que nace con cada una de las obras y al que, al menos aparentemente, no se le da fin. Por otro lado, Ullán subtitula cada libro con un color que, en términos generales, podemos relacionar con la gama predominante en la pintura de cada artista por lo que a Adoración le reserva el blanco. Además, todos contienen una escritura que, no solamente se rebela contra la caja tipográfica en su forma tradicional, sino que va más allá desafiando las reglas gramaticales, de sintaxis y edición de modo que imposibilita la comunicación verbal y aproxima el texto -muchas veces apropiadoa una imagen. Por otro lado, las tareas del poeta y los diferentes artistas se fusionan y confunden a lo largo de las páginas mediante procedimientos plásticos y escriturales variados. ${ }^{14}$ En resumen, se trata de un proyecto muy

tierra- (con Antoni Tàpies), con forma de acordeón, la fusión de escritura e imagen se hace inseparable y la expresión gestual se lleva al extremo. El fondo también es un texto ajeno apropiado: una declaración protocolaria de la Sociedad Constitucional de Madrid de agosto de 1822, sometido a resaltado de enunciados poéticos, con trazado de letras grandes, tachaduras, rasgados del papel en forma de cruces, caligrafiado. En Almario -libro azul- (con Joan Miró) donde, según los expertos en Ullán, se da un punto de inflexión y la letra comienza a adquirir una estructura rotundamente icónica.

${ }^{14}$ Después de una descripción de los seis libros que componen Funeral Mal, Miguel Casado advierte y resume: "Si esta descripción nada cuenta realmente de su objeto, hablar de los poemas aislados traiciona el conjunto de la idea. Es preciso que conste así, aunque en un acercamiento de estas características la traición se haga inevitable. El pie forzado es la pauta que organiza los textos propios de Ullán en casi todos estos libros, la manera de encontrar una estructura que engaste con los distintos elementos. En Adoración cumple ese papel el texto ajeno, ofreciendo sus blancos como molde rítmico del nuevo poema: se exalta así la arbitrariedad y se supone un subterráneo recorrido hacia una motivación oscura. En Acorde, el anagrama, y en Anular, un acróstico. Por fin, en Almario el pie forzado resulta doble: siguiendo el alfabeto, sus 29 textos comienzan sucesivamente con cada letra; también, cada texto lleva en su zona central un nombre común entre exclamaciones, sin más acompañamiento que un artículo. El pie forzado es imán: núcleo en que sedimentan virutas de lenguaje, estructura que permite apropiarse de los elementos dispersos por una fragmentación” Casado, M., Ardicia (Antología 19641994), Madrid, Cátedra, 1994, p. 81. 
complejo y lleno de interrogantes por el que, insistimos, los estudiosos de Ullán han pasado muy de puntillas ${ }^{15}$.

Adoración, por su parte, consta de 26 hojas con texto y 3 aguafuertes de Chillida (se hizo un cuarto que no llegó a incluirse), y abre con una portada en blanco que contiene un pequeño grabado en seco. Dos de los tres aguafuertes son abstractos, y el tercero se trata de una mano entreabierta. La tirada fue de 150 ejemplares ${ }^{16}$, y fue traducido al francés por Marguerite Duras.
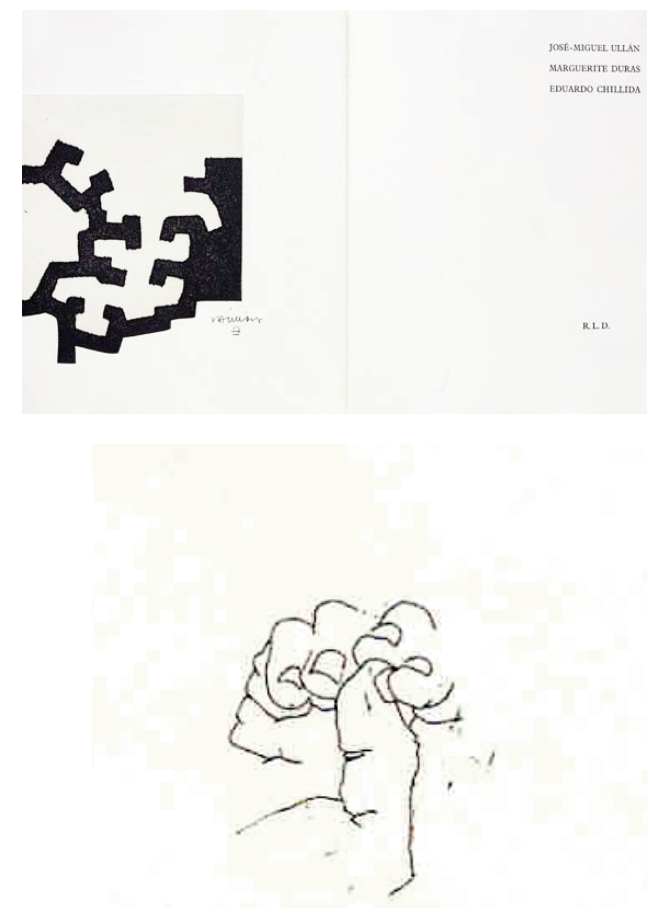

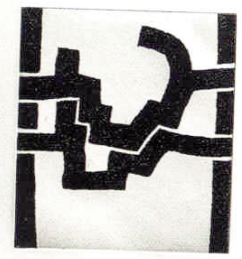

Aguafuertes de Eduardo Chillida para Adoración (Libro blanco), 1977 $32,5 \times 25,5 \mathrm{~cm}$

Respecto al contenido textual, Adoración se compone de fragmentos del Libro de la Sabiduría intercalados con versos cortados del Cántico Espiritual de San

\footnotetext{
${ }^{15}$ Con la salvedad de Acorde, el libro con el artista Vicente Rojo, sobre el que se ha llevado a cabo un trabajo monográfico reciente vid. monográfico sobre Acorde de Mori, "Ley/ Amarillo" en Ferro 2012 op. cit (nota 3) pp. 366-387.

${ }^{16}$ Están numerados del siguiente modo: 1-125 y I-XV además de $10 \mathrm{H}$. C. de la A a la J. Los números 1-35 llevan una suite con los tres grabados y un cuarto aguafuerte diferente. Papel: Auvergne. Medidas: 32,5 x 25,5 cm. Impresor: Atelier Morsang, París Editado por Robert y Lydie Dutrou, París, 1977.
} 
Juan de la Cruz; es decir, un texto apropiado por el escritor, que Ullán no crea sino que reescribe de modo que prácticamente ningún verso puede atribuirse por completo a una de las dos fuentes, ni alberga sentido semántico alguno. Las palabras seleccionadas por Ullán parecen, sin embargo, no estar escogidas aleatoriamente y sugieren algunas pistas para la interpretación del libro como veremos más delante:

puente o hisopo

el tacto

trefe es la faz del eternal $m$

hasta aquí tu oleaje mojó de i

Empero, lo interesante de estos versos no radica únicamente en el contenido, sino también en la distribución de negros y blancos sobre la página, que imita la del juego de llenos y vacíos de la obra gráfica de Chillida, de forma que plantea la escritura como una tarea de composición plástica sobre el papel. Del mismo modo, hojear estos poemas causa el efecto visual de que el negro de unos imita el de otros, o de que las líneas intentan aprovechar o rellenar los blancos de la hoja anterior. "(...) ofreciendo sus blancos como molde rítmico del nuevo poema: se exalta así la arbitrariedad y se supone un subterráneo recorrido hacia una motivación oscura" "17. Es difícil comprobar que esto sea realmente así porque el gramaje del papel no permite hacer el juego de transparencias pero sí se crea un efecto espejo no sólo entre los grabados y las palabras, sino entre los mismos poemas, equiparándose así la escritura y la imagen.
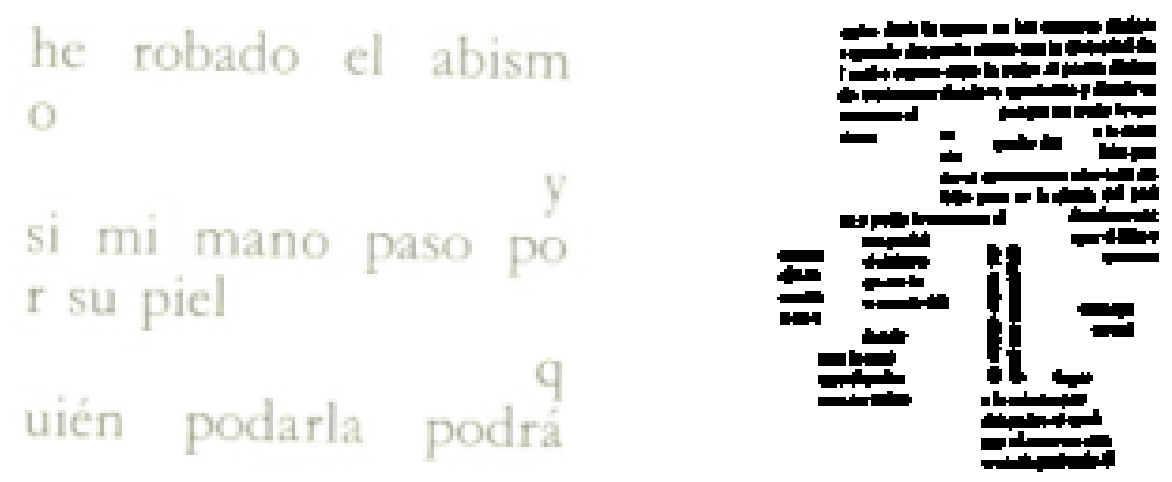

17 Casado, 1994 op. cit. (nota 14). 


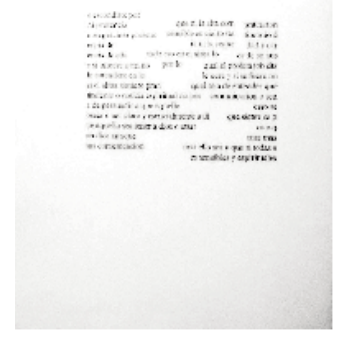

Poemas de Jose-Miguel Ullán. Los versos destacados se exponen y analizan en el artículo. Las siguientes imágenes se han elegido únicamente con el fin de mostrar algunos ejemplos de la distribución textual mencionada. Para ello se ha llevado a cabo una ampliación en la primera y una manipulación en la segunda.

\section{O, dicho de otro modo, Chillida}

Hay un texto de José-Miguel Ullán de 1985 titulado "O dicho de otro modo, Chillida" 18 que, junto a un poema que lo acompaña, resultan ser la única pista que nos ha dejado para enmarcar el contexto y el sentido hacia el que apunta el proyecto Adoración. En este texto, Ullán imagina o sugiere que encuentra un cuaderno de Chillida de los años cuarenta en el que el artista ha copiado a mano el ensayo que Unamuno escribiera en 1900, y en el que da aliento a un joven que parece necesitar consejo ${ }^{19}$. De este modo, Ullán revela la imagen de un Chillida que a finales de los años cuarenta y lleno de incertidumbre sobre su futuro $^{20}$ lee esa epístola que cubre de anotaciones y subrayados como medio de reflexión. Y explica Ullán el por qué de su treta: "E imaginarlo así [a Chillida] es mi sola manera de dialogar con su invención más plena: la de hacernos palpable la versatilidad espiritual, armoniosa, del sentimiento"21.

De estos fragmentos unamunianos que Ullán interpreta interiorizados por el escultor como impulso para salir adelante en su crisis personal, se deducen tres

\footnotetext{
${ }^{18}$ Este texto puede encontrarse publicado en francés en 1985, con el título: "Autrement dit, Chillida" (Chillida, E., y Liebaers, H., (comisario) Europalia '85 España, Bruselas, Musée d'Art Moderne, 1985, pp. 11-13). La adenda del poema "O dicho de otro modo, Chillida" (Poema) se puede encontrar en Ullán, J-M., "Manchas nombradas II", Visto y no visto, Madrid, Ave del Paraíso, 1993, pp. 99-181.

${ }^{19}$ Unamuno, M., “¡Adentro!” (pp. 5-22), en Tres Ensayos, Madrid, Edit. B. Rodríguez Serra, 1900 .

${ }^{20}$ Recordemos que en 1948 Eduardo Chillida decide abandonar sus estudios de arquitectura para dedicarse al arte.

${ }^{21}$ Ullán, J-M., "O, dicho de otro modo, Chillida", Barañano, K. M., (director del programa y editor), Symposium Chillida, Universidad del País Vasco, 1990, p. 31.
} 
ideas que hoy la crítica tomaría por chillidianas: 1. la del anhelo del límite (por inexistente e inalcanzable) como actitud vital; 2 . El concepto de pertenencia al mundo como creación desde lo local -desde la raíz- y las posibilidades de comunicación con el resto de la humanidad; y finalmente, 3 . La dialéctica espiritual del dentro-fuera, exterior-interior, pleno-vacío:

Pon en tu orden muy alta tu mira, lo más alta que puedas, más allá aún, donde tu vista no alcance, donde nuestras vidas paralelas van a encontrase: apunta a lo inasequible $(\ldots)^{22}$.

Morir como Ícaro vale más que vivir sin haber intentado volar nunca... sube, pues, para que te broten alas $(\ldots)^{23}$.

Busca tu mayor grandeza, la más honda, la más duradera, la menos ligada a tu país y a tu tiempo, la universal y secular, y será como mejor servirás a tus compatriotas y coetáneos ${ }^{24}$.

Considera que no hay dentro de Dios más que tú y el mundo, y que si formas parte de éste porque te mantiene, forma también él parte de ti, porque en ti lo conoces (...) Reconcéntrate para irradiar; deja llenarte para que rebases luego (...) Recógete en ti mismo para mejor darte a los demás todo entero e indiviso ... y al darte: "Doy conmigo el universo entero". Buscándolo dentro de ti. "Adentro"25.

Explorando el ensayo de Unamuno, se advierten detalles que, aunque Ullán no los resalta o cita explícitamente, se relacionan con el tema que nos ocupa. En el comienzo del texto, se cita un pasaje del Evangelio de San Mateo, que sigue con: “(...) no dejes que la codicia ahogue a la ambición en ti; vale más que tu ansia por perseguir a cien pájaros que vuelan te broten alas, que no el que estés en tierra con tu único pájaro en mano" (Mat 25) ${ }^{26}$. Ciertamente, esta

\footnotetext{
${ }^{22}$ Palabras de Unamuno ctds. en Ullán 1990, Ibidem pp. 32. En el texto original se encuentran en: Unamuno 1900, op. cit. (nota 19) p. 7.

${ }^{23}$ Palabras de Unamuno ctds. en Ullán 1990, Ibidem pp. 33. En el texto original se encuentran en: Unamuno 1900, Ibidem, (nota 19) p. 12.

${ }^{24}$ Palabras de Unamuno ctds. en Ullán 1990, Ibidem pp. 34. En el texto original se encuentran en: Unamuno 1900, Ibidem, (nota 19) p. 19.

${ }^{25}$ Palabras de Unamuno ctds. en Ullán 1990, Ibidem pp. 35. En el texto original se encuentran en: Unamuno 1900, Ibidem, (nota 19) p. 22.

${ }^{26}$ Unamuno 1900, Ibidem, (nota 19) p. 6. Recordemos, además, que la parábola bíblica de las Diez Vírgenes a la que luego haremos alusión, se recoge igualmente en Mateo 25.
} 
cita de Unamuno recuerda a la frase que Chillida repitió, como un emblema de filosofía de vida en numerosas entrevistas y escritos: "Más vale ciento volando que pájaro en mano"27.

Un Eduardo Chillida joven y perdido acerca del rumbo vital, debatiéndose, posiblemente, entre el querer y el deber, la intuición y la lógica, la arquitectura o la plástica, parece ser respondido por el pensador vasco cuando escribe:

Hay en tu carta una cosa que no me gusta, y es ese empeño que muestras ahora por fijarte un camino y trazarte un plan de vida. ¡Nada de plan previo, que no eres edificio! No hace el plan a la vida, sino que ésta lo traza viviendo. No te empeñes en regular tu acción por tu pensamiento; deja más bien que aquella te forme, informe, deforme y transforme éste. Vas saliendo de ti mismo, revelándote a ti propio; tu acabada personalidad está al fin y no al principio de tu vida; sólo con la muerte se te completa y corona. El hombre de hoy no es el de ayer ni el de mañana, y así como cambias, deja que cambie el ideal que de ti propio te forjas (...). Avanza, pues, $(\ldots) .{ }^{28}$

¿Fijarte un camino? El espacio que recorrerás será tu camino; no te hagas, como planeta en su órbita, siervo de una trayectoria. ${ }^{29}$

Y después de estas citas de Unamuno que dice encontrar en el cuaderno de Chillida, Ullán nos continúa guiando:

Me veo escribiendo un libro, Maniluvios, donde el tacto vacila, se adentra, ve y ordena. Y por aquel entonces, a principios de los desdibujados años setenta, concebí Adoración, un poema de claroscuros, admirablemente grabado por Chillida. ${ }^{30}$

Como vemos, el propio Ullán advierte que se trata de un poema de claroscuros y concebido por la desorientación ${ }^{31}$ lo que nos conduce a la indeterminación poética. Y, en este sentido, recordemos que el valor de la desori-

\footnotetext{
${ }^{27}$ Chillida 2005, op. cit. (nota 6) p. 18.

${ }^{28}$ Unamuno 1900 , op. cit. (nota 19) p. 9.

${ }^{29}$ Unamuno 1900, Ibidem, p. 10.

${ }^{30}$ Ullán 1990, Ibidem p. 35.

${ }^{31}$ De este mismo modo se lo indica a José Ángel Valente: "el artista tiene que estar desorientado, la intencionalidad liquida de raíz el impulso creador" Valente, J. A., "El arte como vacío: conversación con Eduardo Chillida", Elogio del calígrafo. Ensayos sobre arte, Barcelona, Galaxia Gutenberg, 2002, p. 121.
} 
entación y la consecuente capacidad de sorprenderse en cada hallazgo como guía de vida y creación es común en ambos artistas. Así lo afirmaba a menudo Chillida cuando escribía: "Lo hice mejor porque no lo conocía/ e iba cargado de dudas y asombro"32. Por su parte, Ullán habla en repetidas ocasiones (especialmente en Maniluvios $^{33}$ ) de la necesidad de destruir la certidumbre como práctica poética.

Y Ullán continúa con su asociación de situaciones y recuerdos e introduce esta vez a Walter Benjamin para evocar a Chillida una vez más:

Del otro lado de esa luz yo escribí una Ventana melancólica para Eduardo Chillida. En el blanco central del poema, no exactamente escritas, las palabras de Walter Benjamín, su voz bajo el efecto de la mescalina, el 22 de mayo de $1934 .^{34}$

Y Ullán cita, dedicadas de nuevo a Chillida, estas frases de Benjamin en Haschisch que, precisamente, se acababa de publicar en 1974:

Si sintiese yo, ya muerto, añoranza por algún objeto cualquiera de la vida anterior, por ejemplo esta ventana, se me aparece tal y como ahora la veo. Los objetos muertos y presentes pueden despertar una añoranza que no se conoce más que al mira a una persona amada ${ }^{35}$.

Acariciar: hacer que no haya sucedido lo sucedido, lavar la vida en el flujo del tiempo. Este es el auténtico reino de la madre. Peinar: el peine saca por la mañana los sueños de los cabellos ${ }^{36}$.

${ }^{32}$ Chillida 2005, op. cit. (nota 6) p. 20.

${ }^{33}$ Ullán, J-M., Maniluvios, Barcelona, El Bardo, 1972.

${ }^{34}$ Ullán 1990, op. cit (nota 21) p. 36.

${ }^{35}$ Palabras de Benjamin ctds. en Ullán 1990, Ibidem p. 36. El texto original se encuentra en: Benjamin, W., "X. Fritz Fränkel: "Protocolo del intento con mescalina del 22 de mayo de 1934", Haschisch, Madrid, Taurus, 1974, p. 153. "A las diez recibe en el muslo subcutáneamente veinte gramos de Mescalina Merck". Benjamin está a solas a oscuras junto a la ventana. Esta alterado y sensible. El doctor le escucha decir las palabras antes citadas que transcribe en el protocolo.

${ }^{36}$ Palabras de Benjamin ctds. en Ullán 1990, Ibidem p. 36. En el texto original en palabras del médico Fritz Fränkel: "Esa mudanza en el temple de Benjamin se hace perceptible en consideraciones sobre el acariciar, el retrasarse y el peinar. Todos estos modos de comportamiento se asocian más o menos estrechamente a la naturaleza de la madre. Acariciar: hacer que no haya sucedido lo sucedido, lavar la vida en el reflejo del tiempo. Éste es el auténtico reino de la madre. Peinar: el peine saca por la mañana los sueños de los cabellos. Peinar es también trabajo de la madre". Benjamin 1974, Ibidem pp. 155-156. En los apuntes de Benjamin sobre el 
Y de estas citas crípticas brotan palabras cargadas de significado que nos llevan a indagar si acaso el otro lado de esa luz sea el de la página en blanco o si, tal vez sea el de la escritura respecto a la imagen. Del mismo modo, cabría pensar en esa Ventana melancólica a la que se asoma Benjamin como un poema, como una imagen, o bien como un retazo cualquiera de creación indefinido que sufre de melancolía por no poder ser ya ese acceso al mundo perspectiva como el arte de antaño. Por otra parte, podemos aventurar que la razón por la que Ullán vincula esas palabras de Benjamin sobre el universo femenino a través del gesto de peinar los cabellos, tiene relación con el hecho de que El Peine del viento ${ }^{37}$ estuviera empezando a ser instalado justamente el año en que se terminó Adoración.

\section{Re-escribir el Libro (blanco) con la mano}

Ullán decide nombrar este libro Adoración, un título de reminiscencias religiosas que, en el caso de Chillida, adquiere más sentido aún desde el momento en que atribuye a la divinidad el origen de los materiales básicos con los que trabaja: "Tú creaste el tiempo/ el espacio/ la gravedad/ la luz/ y el viento que no vemos" ${ }^{38}$ o cuando dice: "Mi continua rebelión contra las leyes de la gravedad tiene un aspecto religioso" 39 . Por otro lado, sus indagaciones sobre lo liviano y la ingravidez de la materia no son sino una preocupación de naturaleza religiosa que debió de impresionar a Ullán a la hora de diseñar, titular y escoger las palabras del libro que nos ocupa.

Como hemos dicho, Adoración contiene fragmentos tanto del Cántico Espiritual, que Chillida podía recitar de memoria -recordemos también los más de 30 homenajes gráficos que le hace al místico- como del Libro de la Sabiduría. Respecto a este último, los teólogos han visto en él expuesto por primera vez la prueba de la existencia de Dios mediante la contemplación de la naturaleza, es decir, a través de la meditación sobre las cosas del mundo, mediante la lectura del mundo. Un libro cuya estructura, por otro lado, consid-

mismo intento escribe: "Naturaleza de la madre: hacer que no haya sucedido lo sucedido. Lavar la vida en el flujo del tiempo. Labores femeninas: hacer orlas, hacer nudos, trenzas, tejer" Benjamin 1974, Ibidem p. 167.

${ }^{37}$ Sobre el tema de la escultura Los Peines del Viento en relación con la diosa vasca Mari y la representación del universo femenino (oquedad, cabello, madre, mar), remitimos al artículo publicado en este mismo volumen por Ana María Leyra Soriano.

${ }^{38}$ Chillida 2005 op. cit. (nota 6) p. 37.

${ }^{39}$ Oropesa, M. (comisaria), Chillida. Música callada, Ávila, Palacio Los Serrano, 2004, (conversación entre Chillida y Mennekes p. 15). 
eran algunos sigue la regla áurea ${ }^{40}$. A colación de esto, merece la pena recordar que Chillida no empleaba la proporción áurea -evitaba los ángulos rectos y la seguridad de la geometría a la par que desafiaba las certezas de Newton-; le gustaba saber que las reglas existían pero para fascinarse con ellas, poder jugar y explorar sus límites ${ }^{41}$. Romper las normas y sus divinas proporciones: eso es exactamente lo que hace la disposición del texto en Adoración: hibridar el verbo mezclando voces, descomponer estructuras para llevarlas al límite poniendo en jaque el sentido de la lectura.

El elemento central del libro bíblico es el concepto de la Sabiduría divina y su acción en la historia. Para referirse a esto, el libro emplea los términos "Sabiduría" y "Dios" pero los va sustituyendo progresivamente por sus imágenes teológicas mediante vocablos como "palabra" o "mano". Es por eso que entre los pedazos rotos de versos que Ullán dispersa por las páginas de Adoración, podemos leer frecuentemente las palabras "verbo", "tacto" y "mano". Estos son algunos fragmentos del Libro de la Sabiduría en los que se cita a la mano; trozos de estos versos y palabras mezclados con otros es parte de lo que se acierta a leer en los poemas de Ullán:

Pues bien podía tu mano omnipotente,

Que creó el universo de la materia informe (...) (Sabiduría 11, 17).

Porque el desplegar gran poder está siempre en tu mano:

Y ¿quién puede resistir a tu brazo poderoso? (Sabiduría 11, 21).

Y ya al principio, mientras parecían los gigantes orgullosos,

la esperanza del mundo refugiada en una barca

pilotada por tu mano

legó al mundo semilla de una nueva generación (Sabiduría 14, 6).

(...) es imposible escapar de tu mano" (Sabiduría 16, 15)

\footnotetext{
40 “ (...) el libro ha sido compuesto utilizando la divina proporción o regla áurea (...) La extensión de cada una de las secciones del libro se halla en proporción matemática con el resto según la siguiente fórmula: $\mathrm{m}(\mathrm{m}+\mathrm{M})=\mathrm{MM}$, donde la " $\mathrm{m}$ " es cada una de las secciones menores del libro y "M" cada una de las secciones mayores" Wright, A. G., The Structure of the Book of Wisdom 1967 ctdo. en La Santa Biblia. Edición de Evaristo Martín Nieto, Madrid, San Pablo, 2005. Wright recoge, desarrolla estas especulaciones en torno al Libro de la Sabiduría que había iniciado J.M. Rose en Plan and Structure in the Book of Wisdom de 1965.

41 "Para mí la geometría no existe, yo soy un fuera de la ley" Chillida 2005 op. cit (nota 6) p. 66. "La simetría es la seguridad, y ésta está muy cerca de la muerte" Chillida 2005, Ibidem, p. 66.
} 
Por allí pasó un pueblo en masa,

Protegido por tu mano (...) (Sabiduría 19, 8).

En estos versos se resumen algunos de los numerosos valores simbólicos que posee la mano para la tradición bíblica, aplicable también, en muchos casos, a otras culturas y religiones. La mano puede ejercer el poder por sí misma y sin ayuda de la voz (el castigo, la absolución, la solicitud de perdón); maniobrar, manipular o manejar no requieren de la mano pero en su etimología evocan la naturaleza poderosa de este miembro. Por otro lado, la mano es el signo absoluto de la creación: marca inconfundible de identidad artística: Dios insufló vida a sus criaturas con su dedo y con las manos moldeó al primer hombre de barro. La mano es también guía indicadora, señal de compromiso en el matrimonio, medio de las caricias y protege con su bendición, imposición, o dentro de la oquedad que crea cuando se cierra. Y dice al respecto Maderuelo: "El conocimiento del mundo y sus objetos por medio de la mano es tan intenso como lo es la imagen que nos formamos de él a través de la vista"42. Y es que, leídas en términos paisajísticos, Chillida vio en sus surcos, protuberancias, valles y ríos esa naturaleza que San Juan de la Cruz evocaba y así lo expresó en muchos dibujos de manos:

¡Oh bosques y espesuras, plantadas por la mano del Amado!” (San Juan de la Cruz, Cántico, estrofa 4, 1).

Mi amado, las montañas,

los valles solitarios nemorosos, las ínsulas extrañas.

Los ríos sonorosos,

El silbo de los aires amorosos (San Juan de la Cruz, Cántico, estrofa 14, 1-5).

La mano guía los textos de Adoración y no solamente es el medio ejecutor de la escritura y las artes sino que, como sabemos, para ambos artistas la mano es un motivo de reflexión sistemático por sí misma ${ }^{43}$. En el caso de Chillida, contamos con más de 300 dibujos y mas de 100 grabados de manos, además del libro La memoria y la mano con Edmond Jabès (1974-1980).

\footnotetext{
${ }^{42}$ Maderuelo, J., Chillida, elogio de la mano, Cuenca, Museo de Arte Abstracto Español, Fundación Juan March, 2003, p. 7. Sobre este tema también: Félix Duque: "El estupor de la mano" (pp. 27-37) en García Velilla y González Lavagne 2007 op. cit. (nota 9).

43 “(...) puedo aventurarme a asegurar más: casi todas las obras que Eduardo Chillida ha realizado como escultor, como grabador, o como dibujante, exceptuando solamente una serie de desnudos realizada entre 1948 y 1951, cuando aún practicaba la representación antropomórfica, y algún retrato familiar ocasional, tiene como referente último la mano" Maderuelo 2003, Ibidem p.14.
} 
Concretamente, para su amigo Ullán hace dos manos: la de Adoración que se cierra generando espacio cóncavo interior y otra ilustración para Soldadesca de Ullán ${ }^{44}$, que se que se abre hacia lo convexo en gesto de entrega ${ }^{45}$.

El mismo Ullán recordaba cuando explicaba la gestación del proyecto con Chillida hacia 1972 que por aquel tiempo estaba trabajando en Maniluvios ${ }^{46}$. Una obra donde elogia a la mano en sus versos: "JURO/ seguir soñando/ con la mano armada" o "no des paz a la mano" y desde donde invoca la razón del tacto; el tacto como forma de conocimiento en la oscuridad y la visualidad de la mano -continúa ${ }^{-47}$. "Y -finalmente- mi mano vive, mi mano ve".

"Razón de tacto" y "ver con las manos": Todos sabemos que la relación que Chillida establecía con la materia era a través del oído primero y del tacto después. Quizá fue eso también lo que le impulsó a forzarse a escribir con la mano izquierda: para que la mano llegara antes que la razón, por razones de tacto. $Y$ es que, en última instancia, forzarse en dibujar con la mano izquierda es instar la intervención del lóbulo derecho y, por lo tanto, dar cabida a un modo distinto de pensar.

El texto al que Ullán hacía alusión cuando pensaba en Chillida, incluye tres caligramas realizados por Benjamin bajo el efecto de la embriaguez, junto a una reflexión acerca de sus manos: las numerosas opciones de posturas, el control sobre éstas, y la posibilidad de su pérdida ${ }^{48}$. Aparecen así las manos como señal del dominio sobre el cuerpo tanto para el catatónico como para el artista. Así lo observa el médico que parece podría estar describiendo uno de los dibujos de manos de Chillida:

${ }^{44}$ Ullán, J-M., Soldadesca, Valencia, Pre-textos, 1979. Con ilustraciones de Enrique Brinkmann, Eduardo Chillida, Alfonso Fraile, Luis Gordillo, Pablo Palazuelo, Francisco Peinado, Matías Quetglas, Vicente Rojo, Antonio Saura, Eusebio Sempere, Antoni Tàpies y Fernándo Zóbel.

45 "Sabido es todo lo que la mano -su mano- representa a lo largo del desarrollo de su obra. La mano se cierra, es puño: pura interioridad. La mano se abre, es palma: pura forma de darse a los otros, solidaridad. La mano se abre y se cierra, parpadea o late como un ala: la mano es ala, ave, signo de una anunciación. La mano tiene en ese doble movimiento el ritmo del corazón" Valente 2002, "Chillida o la transparencia" (nota 31) p.157.

${ }^{46}$ Ullán 1972 op. cit. (nota 33).

${ }^{47}$ De acuerdo con Miguel Casado, a partir de esta obra comienza a percibirse en Ullán la voluntad de conceder un espacio autosuficiente a la poesía y este proceso requiere la progresiva liberación de la mano. Prólogo a Ondulaciones en Ullán, J-M., Ondulaciones (Poesía reunida (1968-2007), Madrid, Círculo de Lectores, 2008, p. 36.

${ }^{48}$ Recordemos que Chillida envió un dibujo de manos al motorista Andrés Pérez Rubio, campeón de España de 500c que, en 1994 perdió las manos en un accidente cerca de Madrid. No le conocía pero a Chillida le conmovió tanto el suceso que se solidarizó de esta forma con él. El suceso se recogió en la prensa del 17 de marzo de 1994 y la anécdota de Chillida, se puede leer por ejemplo en: Martínez Aguinagalde, F., Palabra de Chillida (Me interesa más conocer que el conocimiento), Bilbao, Universidad del País Vaco, 1998, p. 85 
En el curso del siguiente periodo del intento, que constituye el estadio más profundo de la embriaguez, aparecen posiciones de manos muy peculiares. Benjamin, que está acostado, mantiene, mantiene el antebrazo extendido, la mano lánguida y los dedos algo agarrotados. Entre tanto cambia de posición de tal manera que la mano queda mantenida hacia arriba (...). Hace observar de pronto que no hubiese podido constatar sin sorpresa al abrir los ojos que sus manos estaban en realidad de otra manera a como pensaba que estarían. ${ }^{49}$

Lo que Benjamin recuerda del siguiente modo:

La verdadera posición de mis manos es muy distinta de la que tengo en mi consciencia y que usted puede leer en la expresión de mi rostro. De este modo, surge para usted una tensión enorme entre la expresión de mi rostro y la actitud de mi cuerpo. Esta tensión ejerce sobre usted un poder mágico $(\ldots)^{50}$.

Mi mano es muchas manos

Y se la llama mi mano.

Mi mano es ahora tanto una fuente pública como la reina de Saba. Tiene un pedestal sobre el que puede escribirse lo que se desea como epitafio ${ }^{51}$. Está en cualquier sitio distinto de aquel en el que creo se encuentra. La mano del catatónico y su placer: al mínimo cambio en la enervación une el cambio máximo de representaciones. Ese ahorro es su placer. Es como un dibujante que ha trazado para siempre el contorno de su dibujo y que, por medio de millones de nuevos sombreados saca de él imágenes nuevas. $^{52}$

\footnotetext{
${ }^{49}$ Benjamin 1974 op. cit. (nota 35) p. 158.

${ }^{50}$ Benjamin 1974, Ibidem (nota 35) p. 162.

51 "Mi mano es muchas manos// Y se la llama mi mano. Mi mano es ahora tanto una fuente pública como la reina de Saba. Tiene un pedestal sobre el que puede escribirse lo que se desea como epitafio" Benjamin 1974, Ibidem, p. 162. Estas frases son también citadas por Ullán para referirse a Chillida. Ullán 1990, op. cit (nota 21) p. 36.

${ }^{52}$ Benjamin 1974, Ibidem, pp. 168-169. El médico lo interpreta así parafraseando las palabras de Benjamin: "La auténtica interpretación de la catatonia es la siguiente: Benjamin compara la posición fija de su mano con el contorno de un dibujo que el dibujante ha determinado para siempre. Y así es como a ese dibujante le resulta posible modificar siempre de nuevo o matizar su dibujo por medio de innumerables cambios en el sombreado, así también es posible para el catatónico alterar, por medio de cambios minúsculos en la enervación, los círculos de representación unidos a su actitud" Benjamin 1974, Ibidem, pp. 162-163.
} 
Manos y tacto son materia pero también tiempo ${ }^{53}$ porque, de hecho, llevan inscrito nuestro futuro en la palma y son la partes de la anatomía donde mejor se refleja la edad, además del oficio o el tipo de vida que uno ha llevado: "Tengo las manos de ayer/ me faltan las de mañana" ${ }^{54}$ y también se pregunta en otro momento “¿Con qué manos trabajo?”, es decir, ¿con qué tiempo? ¿en qué dirección? ¿hacia dónde miro? De este modo, al igual que en la sombra, en las manos como materia se concreta el paso del tiempo.

Por otro lado, las manos son los ojos del invidente y la palabra del mudo ${ }^{55}$ : "mis manos al fin ven" dice Ullán. Esas manos son las que nos guían en la oscuridad de la noche permitiéndonos al principio reconocer y después ver, es decir, conocer. El artista se adentra en la creación (como en una cueva $\mathrm{u}$ oquedad, uterina quizá) a ciegas, a tientas con el espacio y la materia situándose ante lo desconocido para finalmente dar (a) luz a la obra. Cito a Chillida: "Cuando empiezo una obra casi no veo a dónde me dirijo. No veo sino cierta figura de espacio de la que, poco a poco, destacan algunas líneas de fuerza" ${ }^{\text {"56 }}$. Entonces, la mano es toda posibilidad de creación en su capacidad de guiar para ver. En su hueco interno -desde el vacío- y junto a la hoja en blanco aguarda, con la lámpara encendida ${ }^{57}$, la llegada de toda oportunidad de gestación.

Ullán subtitula Adoración como "Libro Blanco" por lo que debemos interrogarnos acerca del significado de ese color para él, así como de las atribuciones que le da con respecto a la obra de su ilustrador. Por una parte, en la obra gráfica de Chillida el blanco cumple la función del vacío en la escultura; no un vacío como nada sino todo lo contrario: un vacío místico, un vacíomatriz, positivado y pleno (de luz). Como recuerda Valente pensando en Chillida, el "Génesis" -y toda génesis- requiere que "en el comienzo sea la nada" ${ }^{58}$. Y tanto Chillida como Ullán trabajan con esa idea: a Chillida le intere-

\footnotetext{
53 "No vi el viento vi moverse las nubes/ No vi el tiempo vi caerse las hojas" Chillida 2005, op. cit (nota 6), p. 28.

${ }^{54}$ Chillida 2005, Ibidem, p. 17.

${ }^{55}$ Es interesante recordar que Ullán probablemente tendría frescas las reflexiones entorno a la materialidad de la escritura por la influencia sus clases con Barthes en París. En este sentido, conviene recordar el reportaje de la entrevista que Ullán hizo al pensador francés en el que incluyó unas tomas de una misa en lenguaje de signos. Un ejemplo de la sustitución de lo etéreo del Verbo por el gesto físico de la mano. Ullán, J-M, Entrevista a Roland Barthes. Programa "Imágenes" dedicado a las artes visuales. TVE. 1979.

${ }^{56}$ Chillida 2005, op. cit, (nota 6) p. 77.

${ }^{57}$ Alusión a la parábola bíblica de las Diez Vírgenes (Mateo 25:1) por la que la lámpara de aceite encendida es una metáfora de la espera preparada, prudente y consciente con el objetivo de, en última instancia, someterse a la procreación.

${ }^{58}$ Valente 2002, "El arte como vacío: conversación con Eduardo Chillida", op. cit (cita 31) p. 122.
} 
sa lo que pasa entre las formas, mientras que a Ullán le interesa el hueco blanco que bordea las letras. Mientras uno desocupa el espacio ${ }^{59}$ el otro desescribe la página. $\mathrm{Y}$ es que, en el fondo, todo problema sobre el vacío-pleno y positivonegativo es una reflexión sobre la experiencia de la escritura (incluso en el caso del vaciado de Tindaya). Por otro lado, para Ullán la creación plástica nace precisamente cuando se "queda en blanco" cuando no le salen las palabras pero la mano quiere seguir y, por eso, refiriéndose seguramente a la escritura dice: "alzarte, de blanco en blanco, entre las garras a menudo cómplices de un aguilucho nocturno," ${ }^{60}$. Y esos son sus "Agrafismos": la voz del ágrafo, la negación de toda verbalidad, la mano como voz.

\section{Conclusión}

El poema que José-Miguel Ullán escribe a Chillida parece un resumen de los elementos creativos vinculantes de los dos artistas. Además de citar explícitamente la obra Adoración, en "O, dicho de otro modo, Chillida (Poema) ${ }^{" 61}$ se habla del concepto de desprendimiento como la posibilidad de vaciarse para llenar y así crear: esculpir quitando con el vacío/blanco en el caso de Chillida, o desescribir en el caso de Ullán. Surgen las dicotomías giratorias que cita Ullán a menudo en su poesía y que, como contrarios, permiten la creación y la percepción: luz/oscuridad y blanco/negro ${ }^{62}$. Así se pone de manifiesto la idea de crear como dar luz, y esa luz opera tanto con el blanco como con el negro. Por otro lado, está el silencio que interroga a la obra y que le hace hablar por la mano y los materiales que toca: hierro, barro, papel. Esa

\footnotetext{
${ }^{59}$ Quitar-desescribir: "Casi todo se arregla quitando// Como no quites/ vas listo // Como no borres/ vas listo" Chillida 2005 op. cit. (nota 6) p. 73.

60 "Muerte reticulada, vaivén enfermo de escucharte / alzarte, de blanco en blanco, entre las garras a menudo cómplices de un aguilucho nocturno, por la espiral de esa lejanía que ahora, que ya no es casi, de derretible amor, te obliga, ante algunos, otras palabras dadas, de bruces, a reconciliar y a asentir: // Si degollables fuesen como bosnios o kurdos, ¡a/ por ellas!" Ullán 2009 "Razón de nadie" op. cit. (nota 47) p. 910.

${ }^{61}$ Es curioso apuntar el hecho de que José-Miguel incorpore este poema en su libro Manchas nombradas dada la naturaleza de esta obra que, planeada con otros pintores (Sempere, Saura, Palazuelo entre otros), se supone contenía poemas inspirados en sus obras plásticas. Sin embargo, finalmente Ullán lo publicó sin incluir ninguna de las imágenes que habían dado lugar a los poemas por lo que cada página contiene un texto desplazado dejando en blanco el lugar que, se supone, tendría que ocupar una imagen, quedándose el texto sin referencia. Ullán, J-M., Manchas nombradas, Madrid, Editorial nacional, 1984 (prólogo de Antonio Saura).

62 “(...) En blanco, ante el silencio/ Giratorio/ En blanco, y no de ti, / Giratorio/ velar/ A oscuras”. Ullán 1993 op. cit. (nota 18) p. 144.
} 
mano, lesku, -símbolo de creación primigenia-que espera con la lámpara encendida la revelación, y que tienta y palpa para ver a través de ellas y poder, así, ejecutar el grafismo. Así se pone en relieve la idea de creación como espera pero con la lámpara encendida -preparado: lápiz en mano-, aguardando a lo que aún no se conoce, lo inefable.

Por cuestiones de espacio se han seleccionado únicamente los fragmentos más significativos. Hay que tener en cuenta que, en el poema completo original, puede leerse del revés la palabra "CHILLIDA" en mayúsculas y acrósticos. Y nos preguntamos si no será este poema esa Ventana melancólica que Ullán dice escribir para Chillida entre las palabras no explícitas de Benjamin y situadas en el blanco de un poema.

$(\ldots)$

Aquí, está, consumado, el elogio del desprendimiento.

Contra la posesión.

Nada está, en este instante materializado, sujeto a la figura del origen ni a la forma del vértigo postrero; la mano, ensimismada, escucha

el rumor de lo intacto, el rumor de lo ausente, nuevo mundo que halló su centro móvil en la doblez elemental del gesto: apagar y encender

(...)

De ahí su silencio en sobresalto, que interroga y contempla al que se acerca ahora para luego alejarse al mismo tiempo.

Su tiempo es el espacio de la sangre. El rumor de lo errante. La huella de la libertad

giratoria.

Está a la luz del sueño, esmaltado en lo oscuro, en el fondo del aire -llevándose

los labios a los dedos.

(...)

Chillida

(...)

Golpea como música en plena duermevela. Golpea con el fin de desterrar la imagen fija, prefijada, para quebrar su soledad de barro, su salud de hierro, su espejismo de arena, su volubilidad de papel.

Amasa los añicos, los fragmentos, las esencias, las ínsulas extrañas, todo aquello que puede palpitar en el tibio desierto de una mano tendida. 
Una mano tendida a la revelación.

De ahí su fuerza cordial.

No el cómodo aspaviento, sino la laboriosa espera.

La lámpara encendida.

El horizonte.

La dicha de aguardar, no en vano, lo más inevitable del sueño: la parábola.

(...)

En las líneas de sombra

golpea.

Dar fe

de lo que queda en pie.

Ira desvanecida. Adoración.

Fracción plena.

Laberinto de la mirada.

Signos de raíz aérea.

Reposo del destierro mental. Cicatriz en calma. El lugar.

El lugar sin lugar.

Chisporrotea la semilla rústica cuando amanece el canto.

Chillida rasga las palabras con sus tijeras.

Chillida traza el ritmo de las campanas.

Chillida resquebraja los caminos trillados.

Con la mano tendida, aguarda. Lo que no tiene nombre ${ }^{63}$.

Chillida y Ullán se cruzan en un lugar intermedio entre el campo del artista plástico y el poeta: en un libro; en definitiva, en el espacio común del papel (blanco) como punto de partida, y permitiendo así que ambos puedan operar sobre el territorio del otro ${ }^{64}$.

Tradicionalmente, un libro se escribe, luego se ilustra y con la ilustración viene el lustre, viene la "iluminación" de la escritura. En Adoración el texto se imagina y la imagen se escritura y andamos desorientados -como nos advirtió de antemano Ullán- acerca de quién ilustra a quién en este lío de claroscuros donde se confunden también los límites "laocoontianos" entre lo verbal y lo

\footnotetext{
${ }^{63}$ Ullán "Manchas nombradas II" en Visto y no visto, op. cit. (nota 18) pp. 99-181.

${ }^{64}$ El mismo Chillida decía que cuando, por ejemplo, trabajaba en un homenaje, procuraba ponerse en el espacio del otro y eso es lo que va a hacer que la obra sea distinta cada vez.
} 
visual. Y se pregunta Chillida a propósito de esto: “¿No será el límite una frontera no sólo entre densidades, sino también entre velocidades?" ${ }^{65}$ : Colisión del tiempo y del espacio; colisión verbo-visual y poético-espacial. Porque, además, de esta fusión espacio-temporal, y al contrario que en sus obras públicas, en Adoración se conjuran la mirada vertical ${ }^{66}$ que requiere la plástica de los aguafuertes con el espacio íntimo, cercano, de contacto, "que queda a mano", de la horizontal que caracteriza al libro. Y esto sucede especialmente cuando se trata un libro de contenido religioso con reminiscencias bíblicas en el que la grandiosidad del verbo (la palabra, el aire) hecho carne (materia, tinta, papel) exige cierto recogimiento. Adoración es un libro pero no se llena de discurso temporal sino del tiempo propio del libro como espacio que exige un recorrido con las manos. Es decir, se construye a dos velocidades: la de la escritura y la de la imagen ${ }^{67}$.

${ }^{65}$ Chillida 2005, op. cit (nota 6), p. 54.

${ }^{66}$ Sobre el asunto del dibujo horizontal, en Notas sobre el dibujo entendido como suelo o viceversa, Agustín Valle reflexiona "sobre el dibujo considerado como una estructura horizontal, como un plano de superficie anterior a la verticalidad pictórica, y donde se ahonda en estas cualidades del dibujo como solar de la pintura mediante distintos ejemplos tomados de diferentes periodos artísticos". (par 1) http://reacto.webs.ull.es/pg/n1/9.htm\#_ftn2. Y en este sentido, Benjamin se plantea: "Una imagen debe estar en posición vertical ante el observador. Un mosaico, en horizontal a sus pies. A pesar de esta distinción, es costumbre considerar las artes gráficas simplemente como pinturas. Sin embargo, la distinción es muy importante y de gran alcance (...). Podríamos decir que hay dos secciones a lo largo de la sustancia del mundo: la sección longitudinal de la pintura y la sección transversal de ciertas piezas de arte gráfico. La sección longitudinal es representacional; de alguna manera, contiene los objetos. La sección transversal parece simbólica: contiene los signos. ¿O es sólo cuando leemos que situamos la página horizontalmente ante nosotros? ¿Y existe algo así como una posición vertical original para la escritura -digamos, por ejemplo, para el grabado en piedra?"; "A picture must be held vertically before the observer. A mosaic lies horizontally at his feet. Despite this distinction, it is customary to regard the graphic arts simply as paintings. Nevertheless, the distinction is very important and far-reaching (...). We might say that there are two sections through the substance of the world: the longitudinal section of painting and the cross-section of certain pieces of graphic art. The longitudinal section seems representational; it somehow contains the objects. The cross-section seems symbolic: it contains signs. Or is it only when we read that we place the page horizontally before us? And is there such as an original and vertical position for writing -say, for engraving in Stone?" Benjamin, W., (, M. y , M. W., editores), "Painting and the Graphic Arts", Selected Writings, Volume 1: 1913-1926, p. 82.

${ }_{67}$ ' (...) lo que emparenta el arte, lo que tienen en común todas las artes, es que están obligadas a presentar dos componentes que no pueden faltar: la poesía (...) y una dosis de construcción; si no, no hay arte" Chillida, op. cit. (nota 6), p. 77. Y más a delante insiste: "Cuando leo poesía estoy funcionando en el tiempo, pero también en el espacio" Ibidem p. 86. 